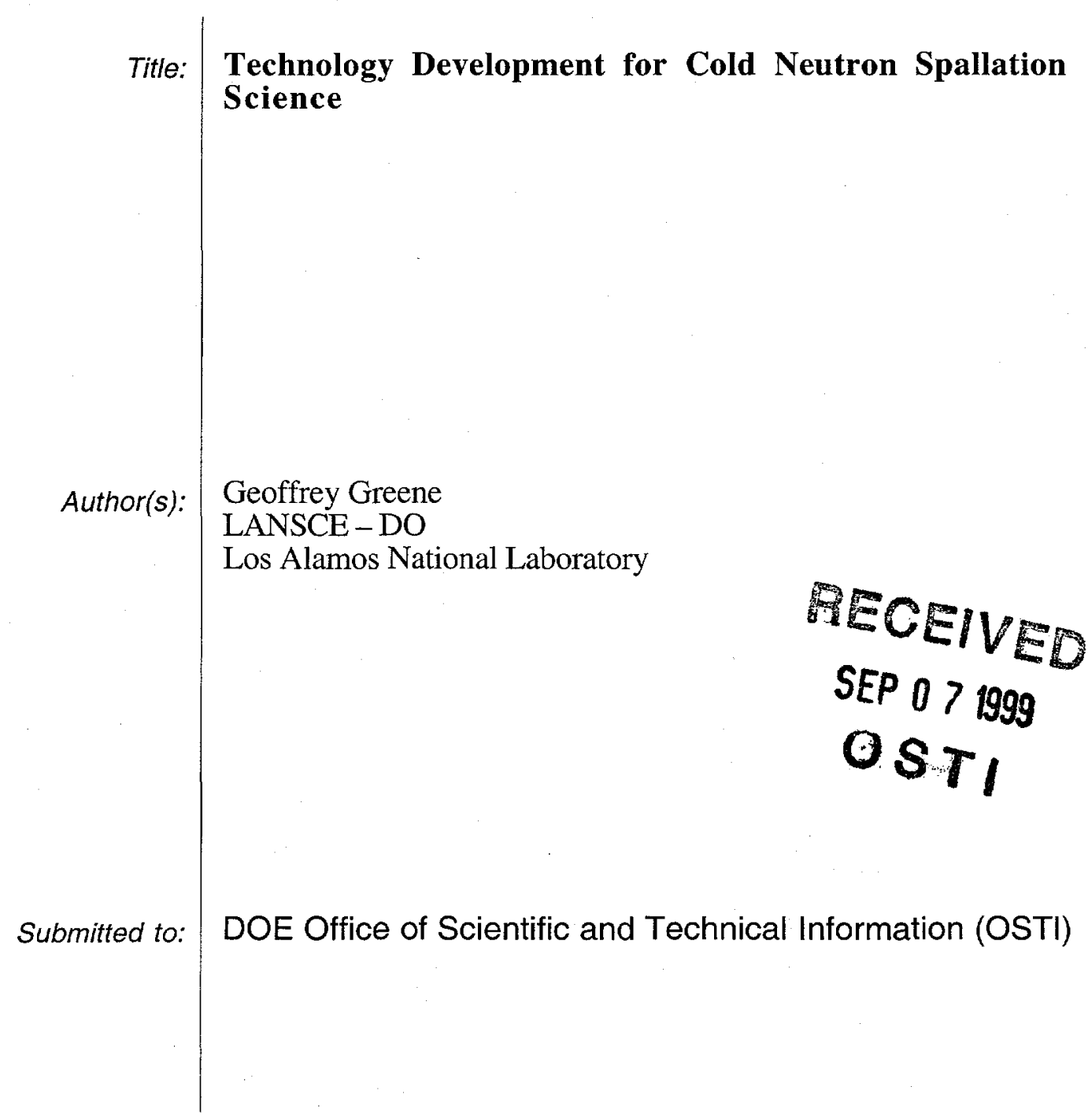

Los Alamos National Laboratory, an affirmative action/equal opportunity employer, is operated by the University of California for the U.S. Department of Energy under contract W-7405-ENG-36. By acceptance of this article, the publisher recognizes that the U.S. Government retains a nonexclusive, royaltyfree license to publish or reproduce the published form of this contribution, or to allow others to do so, for U.S. Government purposes. Los Alamos National Laboratory requests that the publisher identify this article as work performed under the auspices of the U.S. Department of Energy. Los Alamos National Laboratory strongly supports academic freedom and a researcher's right to publish; as an institution, however, the Laboratory does not endorse the viewpoint of a publication or guarantee its technical correctness. 


\section{DISCLAIMER}

This report was prepared as an account of work sponsored by an agency of the United States Government. Neither the United States Government nor any agency thereof, nor any of their employees, make any warranty, express or implied, or assumes any legal liability or responsibility for the accuracy, completeness, or usefulness of any information, apparatus, product, or process disclosed, or represents that its use would not infringe privately owned rights. Reference herein to any specific commercial product, process, or service by trade name, trademark, manufacturer, or otherwise does not necessarily constitute or imply its endorsement, recommendation, or favoring by the United States Government or any agency thereof. The views and opinions of authors expressed herein do not necessarily state or reflect those of the United States Government or any agency thereof. 


\section{DISCLAIMER}

Portions of this document may be illegible in electronic image products. Images are produced from the best available original document. 


\title{
Technology Development for Cold Neutron Spallation Science
}

\author{
Geoffrey L. Greene
}

\begin{abstract}
This is the final report of a Laboratory-Directed Research and Development (LDRD) project at the Los Alamos National Laboratory (LANL). The purpose of the activities supported by this project were the development of new techniques; both experimental and theoretical that will allow more effective exploitation of spallation neutron sources.
\end{abstract}

\section{Background and Research Objectives}

Spallation neutron sources are accelerator based which typically provide intense pulses of neutrons. This is in contrast to continuous neutron sources such as reactors. One can more effectively utilize spallation neutron sources by increasing the peak intensity of the pulse or by designing apparatus that can more efficiently utilize the pulsed nature of the spallation source. It was the goal of this work to investigate technologies that address both of these issues.

\section{Importance to LANL's Science and Technology Base and National R\&D Needs}

LANL has determined that the spallation neutron source at LANSCE is one of the major strategic thrusts of the institution. In addition, DOE has committed to building a major new spallation source (SNS) at Oak Ridge. The development of new technologies to exploit spallation neutron sources will have an impact on the programmatic work at LANSCE as well as the utilization of the SNS as a national user facility.

\section{Scientific Approach and Accomplishments}

The purpose of this project is to identify and develop novel technologies that enhance and exploit the unique capabilities of pulsed (spallation) cold-neutron sources. The use of spallation neutron sources can be enhanced by increasing the "useful" intensity of the neutron pulse. This can be done in two ways: The first approach is to make the incident proton pulse more intense. The second approach is to make the target/moderator

*Principal Investigator, e-mail: glg@lanl.gov 
system more efficient or more appropriately matched to the experiment. DOE/Defense Programs is currently supporting a major upgrade to the Los Alamos Neutron Science Center (LANSCE) spallation source using the first approach.

Our LDRD project has supported moderator studies to address the second approach. The work involved the application of Monte Carlo codes to assess the performance of cryogenic neutron moderators. The project also supported the development of novel technologies that exploit pulsed neutron sources. An essential feature of a pulsed source is the high phase-space density of the pulse. We have developed a new method to allow the high intensity of the short pulse to be transformed into a very narrow range of neutron momenta for neutron reflectometery. The technique involves the rapid $(20-\mathrm{Hz})$, extremely well controlled (less than 1 arc-minute accuracy) oscillation of the reflectometry sample in synchrony with the spallation target. A detailed engineering study of the technique has been carried out. The final design (including fabrication drawings) of an apparatus to demonstrate the method has been completed and will be tested in FY99. 